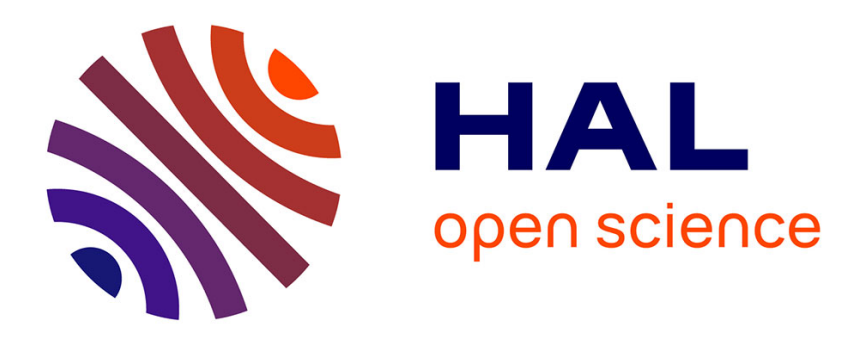

\title{
Ultrasonic Resonance of Metallic Spheres at Elevated Temperatures
}

\author{
W. Johnson
}

\section{To cite this version:}

W. Johnson. Ultrasonic Resonance of Metallic Spheres at Elevated Temperatures. Journal de Physique IV Proceedings, 1996, 06 (C8), pp.C8-849-C8-852. 10.1051/jp4:19968183 . jpa-00254620

\section{HAL Id: jpa-00254620 https://hal.science/jpa-00254620}

Submitted on 1 Jan 1996

HAL is a multi-disciplinary open access archive for the deposit and dissemination of scientific research documents, whether they are published or not. The documents may come from teaching and research institutions in France or abroad, or from public or private research centers.
L'archive ouverte pluridisciplinaire HAL, est destinée au dépôt et à la diffusion de documents scientifiques de niveau recherche, publiés ou non, émanant des établissements d'enseignement et de recherche français ou étrangers, des laboratoires publics ou privés. 


\title{
Ultrasonic Resonance of Metallic Spheres at Elevated Temperatures $(1)$
}

\author{
W. Johnson \\ Materials Reliability Division, National Institute of Standards and Technology, 325 Broadway, Boulder, \\ CO 80303, U.S.A.
}

\begin{abstract}
A unique ultrasonic system has been constructed for measuring resonant frequencies and damping of metallic spheres at elevated temperatures. This system employs electromagneticacoustic transduction, with a solenoid coil surrounding the sphere in a uniform magnetic field. Temperature is measured with an optical pyrometer. Since the acoustic and temperature measurements are noncontacting, the uncertainties associated with external damping are relatively small. The resonant frequency and $Q$ of the sample are determined by digital analysis of the ring-down following a single driving tone-burst. High-temperature measurements on pure polycrystalline aluminum are presented.
\end{abstract}

\section{INTRODUCTION}

Ultrasonic studies of material properties above a couple of hundred degrees Celsius are relatively rare because of the thermal limitations of piezoelectric transducers and mechanical coupling agents. However, in recent years, developments in noncontacting transduction techniques, especially laser and electromagnetic-acoustic, have made elevated temperatures more accessible. This report describes a technique for performing resonance measurements on spheres at elevated temperatures using an unusual electromagnetic-acoustic transducer (EMAT) [1]. Electromagnetic-acoustic excitation is employed instead of laser excitation because it has the advantage of being narrow-banded and, therefore, more easily providing information on the frequency dependence of elastic constants and damping. A resonance technique has the advantage over pulsed-wave techniques of providing accurate direct measurements of damping without corrections for diffraction.

\section{TRANSDUCER AND FURNACE}

Figure 1 presents a schematic diagram of the EMAT and sample. A spherical metallic sample with a diameter between $6.1 \mathrm{~mm}$ and $6.6 \mathrm{~mm}$ is centered in a $15-\mathrm{mm}$-long coil $C$ consisting of 65 turns of platinum wire. The sample is supported by an alumina tube $D$. An $80-\mathrm{mm}$-long alumina tube (not shown) surrounds tube $D$ and the coil. This tube has a number of axially oriented bores in its wall to accomodate a tantulum direct-current heating wire and has a molybdenum sheet lining its inner surface to reduce direct transmission of light from the heater wires to the pyrometer described below. Surrounding the heating tube are several molybdenum heat shields and an outer 38-mm-diameter stainless-steel heat shield separated by alumina felt. Two water-cooled 5.1-cm $\times 5.1$ $\mathrm{cm} \times 2.5-\mathrm{cm} \mathrm{Nd}-\mathrm{Fe}-\mathrm{B}$ permanent magnets $E$ outside the stainless-steel shield provide the static field necessary for electromagnetic-acoustic transduction. The polarizations of the magnets are in the same direction, perpendicular to the axis of the coil. The entire furnace and magnets are contained in a turbo-pumped vacuum chamber.

The temperature of the sample is measured with an optical pyrometer that has a range of $100-1000{ }^{\circ} \mathrm{C}$. Light emitted by the surface of the sample passes through a sapphire $\operatorname{rod} G$ and a fiber

(1) Contribution of NIST. Not subject to copyright in the United States. 

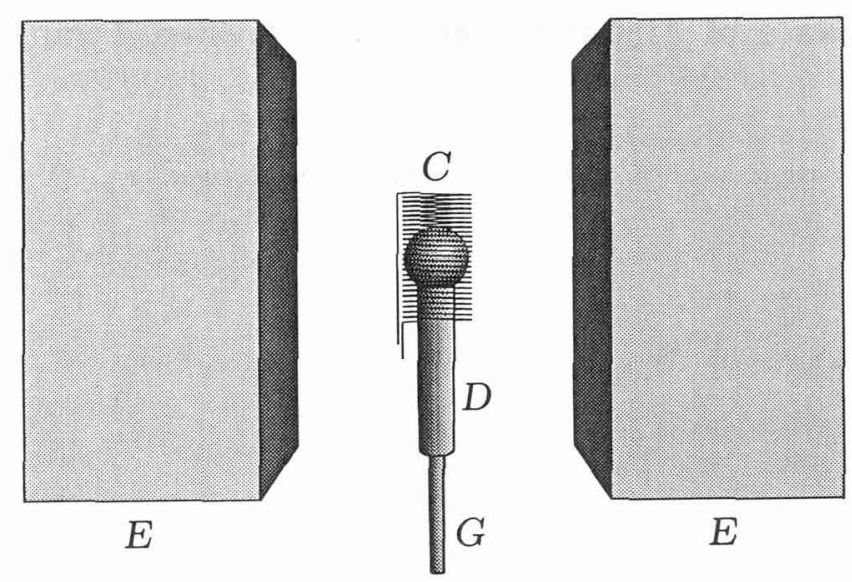

Figure 1: Schematic diagram of EMAT and sample. $C$ : EMAT coil. $D$ : tube supporting spherical sample. $E$ : Nd-Fe-B magnets. $G$ : sapphire light pipe.

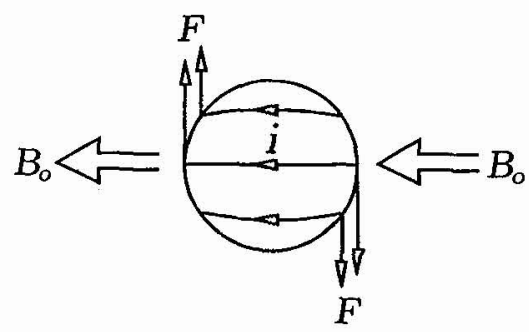

Figure 2: Transduction mechanism for the EMAT depicted in Fig. 1. Oscillating currents in the coil induce currents $i$ in the sphere, which result in Lorentz forces $F$ in the presence of the static magnetic field $B_{0}$.

optic cable to the pyrometer. An approximate black-body configuration is created by surrounding the sapphire rod with a $37-\mathrm{mm}$-long $\mathrm{Ni}-\mathrm{Cr}$-Fe tube (inside tube $D$ ) that is almost completely blocked off at one end by the sample.

Figure 2 illustrates the physical mechanisms involved in the transduction. An alternating current passing through the coil induces eddy currents $i$ around the circumference of the sphere. This movement of charge carriers in the static magnetic field $B_{0}$ results in Lorentz forces $F$ that are parallel to the axis of the coil. If the sample is driven at one of the resonant vibrational frequencies, it will continue to vibrate for some time after the excitation is stopped. Detection of these resonant vibrations is achieved through essentially the reverse of the generation mechanism: movement of the sample in the magnetic field causes charge carriers to experience Lorentz forces, thus inducing currents in the sample which, in turn, induce currents in the coil.

Since the forces depicted in Fig. 2 have both azimuthal and radial components, torsional and spheroidal modes of the sphere $[1,2]$ are excited and detected by the EMAT. The shear velocity of isotropic materials can be determined directly from the measured frequencies of torsional modes, and the longitudinal velocity can be determined numerically from a torsional frequency and a spheroidal frequency if dispersion is negligible over the frequency range spanned by the two resonances [1].

\section{MEASUREMENT TECHNIQUE}

The electronics used to excite and detect resonant vibrations of the samples are similar to those described by Johnson, Auld, and Alers [3]. A synthesizer provides a continuous sine wave to a gated amplifier and a superheterodyne phase-sensitive receiver. The gated amplifier provides a tone burst to the EMAT, typically 2-100 V peak-to-peak and 1-5 ms in duration. The receiver is connected 
to the EMAT through an active diplexer that breaks the connection while the gated amplifier is driving the sample. The processing of the radio-frequency signal by the receiver is similar to that of a lock-in amplifier, yielding the time-dependent amplitudes of the "in-phase" and "out-of-phase" components, $V_{1}$ and $V_{2}$. If the resonant ring-down has a frequency $\omega_{r}$ and decays exponentially with time $t$, the receiver outputs are given by [1]

$$
\begin{aligned}
& V_{1}(t)=A_{o} \exp (-\alpha t) \cos \left[\left(\omega_{o}-\omega_{r}\right) t-\phi\right] \\
& V_{2}(t)=A_{o} \exp (-\alpha t) \sin \left[\left(\omega_{o}-\omega_{r}\right) t-\phi\right],
\end{aligned}
$$

where $\alpha$ is a constant, $\omega_{0}$ is the frequency of the synthesizer, and $\phi$ is a constant phase shift unintentionally introduced in the receiver. Fig. 3 shows examples of $V_{1}$ and $V_{2}$ from an annealed polycrystalline pure aluminum sphere at room temperature. In this figure, the time is defined to be zero at the beginning of the 5-ms tone burst. The driving frequency is $\sim 27 \mathrm{~Hz}$ above a resonant torsional frequency $(899 \mathrm{kHz})$, so $V_{1}$ and $V_{2}$ have $\sim 27 \mathrm{~Hz}$ beats after the tone burst. If $\omega_{0}$ were exactly equal to $\omega_{r}, V_{1}$ and $V_{2}$ would decay monotonically with time [1].
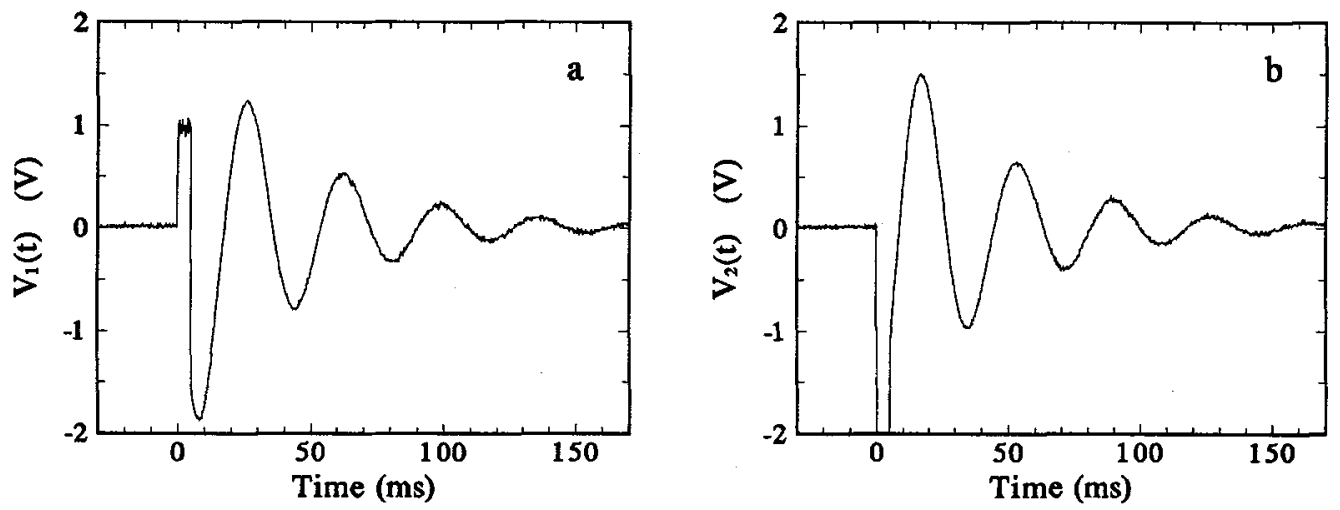

Figure 3: Examples of receiver outputs, $V_{1}(t)$ and $V_{2}(t)$, from a pure polycrystalline aluminum sphere with the driving frequency $\sim 27 \mathrm{~Hz}$ above a torsional resonance $(899 \mathrm{kHz})$.

The two processed signals from the receiver are digitized by an oscilloscope and passed over an IEEE-488 interface to a computer, which also controls other parameters of the system, including driving frequency, amplifier and receiver gains, pulse width, and heater current. The computer is used to calculate the time-dependent amplitude $A(t)$ and relative phase $\theta(t)$ of the signal given by

$$
\begin{aligned}
A(t) & =\left(V_{1}^{2}+V_{2}^{2}\right)^{1 / 2} \\
\theta(t) & =\arctan \left(V_{2} / V_{1}\right) .
\end{aligned}
$$

Since the arctangent operator is defined to yield values between $-\pi / 2$ and $\pi / 2, \theta(t)$ will have periodic discontinuities of $\pi$ if $\omega_{0}$ is not sufficiently close to $\omega_{r}$. These discontiuities are numerically removed to provide a relative phase $\theta^{\prime}(t)$ that is approximately a straight line. With $V_{1}$ and $V_{2}$ given by Eqs. (1) and (2),

$$
\begin{aligned}
& A(t)=A_{o} \exp (-\alpha t) \\
& \theta^{\prime}(t)=\left(\omega_{o}-\omega_{r}\right) t-\phi .
\end{aligned}
$$

Figure 4 shows $A(t)$ and $\theta^{\prime}(t)$ calculated from the data of Fig. 3. The $Q$ of the resonance can be calculated from an exponential least-squares fit of $A(t)$ and the fundamental relation $Q=\omega_{r} /(2 \alpha)$. The resonant frequency can be calculated from a linear least-squares fit of $\theta^{\prime}(t)$. Thus, the driving frequency need not be exactly equal to the resonant frequency to perform an accurate measurement. It is necessary only that the tone burst have a significant Fourier frequency component at the resonant frequency. The central lobe of the Fourier spectrum of a tone burst with duration $T_{o}$ will 

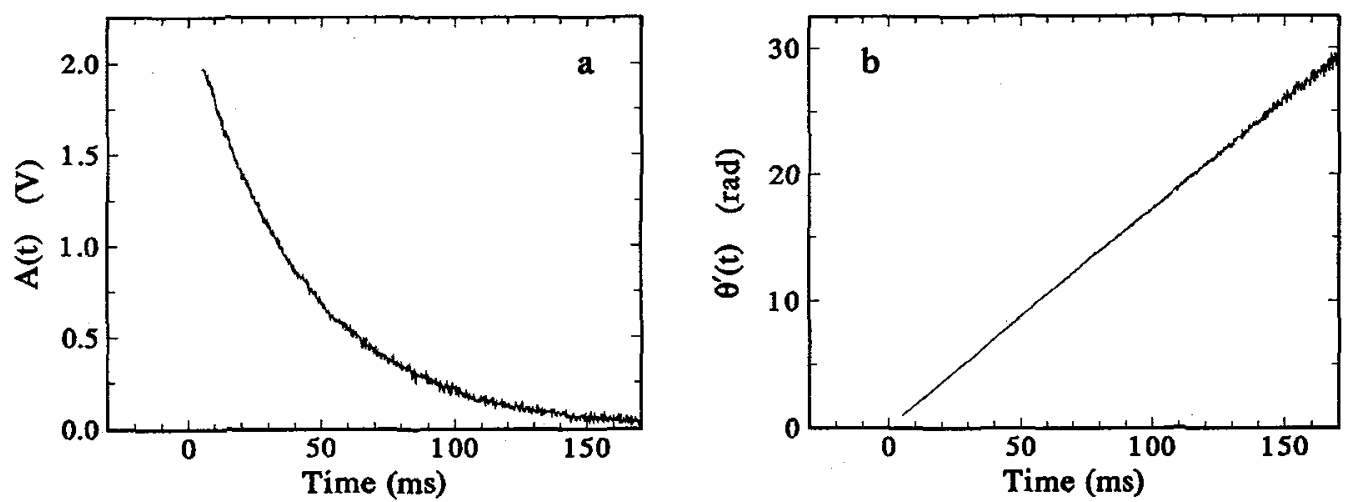

Figure 4: Signal amplitude (a) and phase (b) calculated from the data of Fig. 3.

span a frequency range equal to $2 / T_{o}$ [1]. Therefore, for the $5 \mathrm{~ms}$ tone burst of Fig. 3 , the central lobe is $\sim 400 \mathrm{~Hz}$ wide.

To perform measurements as a function of temperature, the driving frequency is adjusted by the computer every few seconds to approximately match the resonant frequency. Figure 5 shows an example of high-temperature measurements of the lowest-frequency torsional mode of a $6.15 \pm 0.05-\mathrm{mm}$ diameter polycrystalline $99.999 \%$ aluminum sphere. The sample was fabricated by machining on a lathe into an approximate sphere, manually polishing in a brass cone with alumina powder, and then annealing to $420^{\circ} \mathrm{C}$ in the EMAT/furnace to induce recrystallization. A discussion of the physics related to the data of Fig. 5 is beyond the scope of this paper. With respect to the technique, the heating (solid) and cooling (dashed) curves illustrate the good reproducibility of the measurements. The small values of $Q^{-1}$ at the lower temperatures (reaching $5 \times 10^{-6}$ at room temperature) illustrate that little background damping is introduced through mechanical contact to the sample.
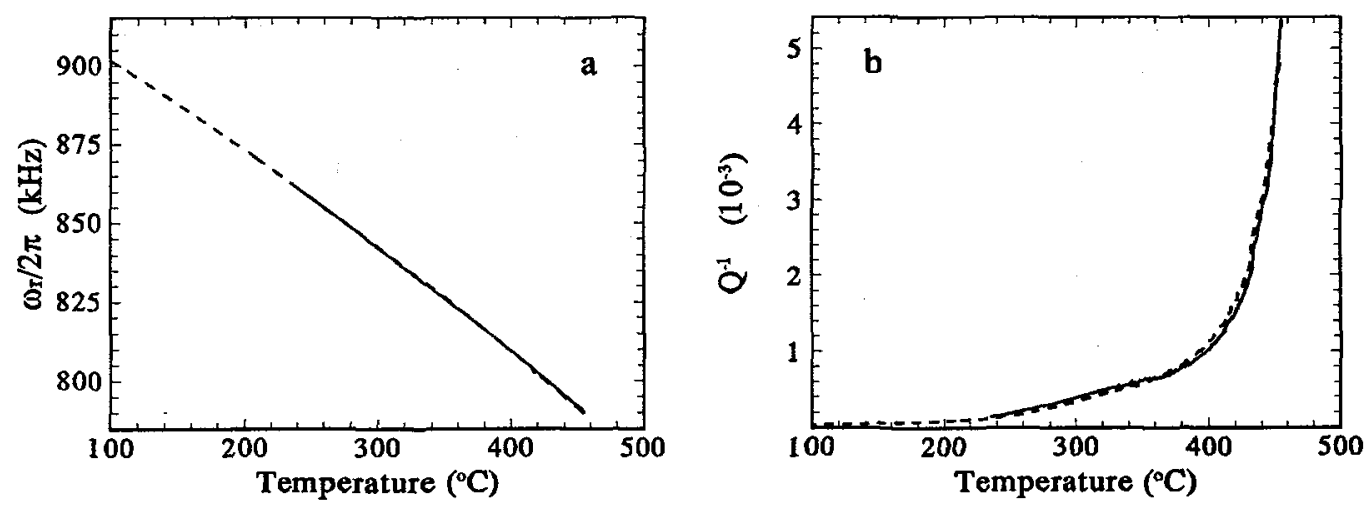

Figure 5: Resonant torsional frequency $\omega_{r} /(2 \pi)$ (a) and $Q^{-1}$ (b) as a function of temperature in an annealed pure polycrystalline aluminum sphere. Heating and cooling data are indicated by solid and dashed lines, respectively.

\section{References}

[1] W. L. Johnson, S. J. Norton, F. Bendec, and R. Pless, J. Acoust. Soc. Am. 91 (1992) 2637-2642.

[2] Y. Sato and T. Usami, Geophys. Mag. 31 (1962) 15-24.

[3] W. L. Johnson, B. A. Auld, and G. A. Alers, J. Acoust. Soc. Am. 95 (1994) 1413-1418. 